\title{
Humoral immune response of flounder to Edwardsiella tarda: the presence of various sizes of immunoglobulins in flounder
}

\author{
Jong-Deuk Bang ${ }^{1}$, Jin-Woo Kim ${ }^{1}$, Saeng-Dong Lee ${ }^{1}$, Su-Il Park ${ }^{2}$, Sae-Gyu Chun ${ }^{2}$, \\ Choon-Soo Jeong ${ }^{3}$, Jeong-Woo Park ${ }^{3{ }^{*}}$ \\ ${ }^{1}$ Pathology Division, National Fisheries Research \& Development Agency, Kijang, Pusan 626-900, Korea \\ ${ }^{2}$ Department of Fish Pathology, Pusan National Fisheries University, Pusan, Korea \\ ${ }^{3}$ Department of Microbiology, College of Natural Science, University of Ulsan, Ulsan, Kyongnam 680-749, Korea
}

\begin{abstract}
Antisera obtained from flounder Paralichthys olivaceus immunized with Edwardsiella tarda were fractionated using Sephacryl S-300 gel filtration. The flounder was found to contain various sizes of immunoglobulins (Igs) ranging from $<200$ to $>700 \mathrm{kDa}$. These Igs were combined into 3 pools according to molecular weight; pool l consisted of high molecular weight (HMW) Igs of $>700 \mathrm{kDa}$, pools II and III consisted of low molecular weight (LMW) Igs of 230 to $700 \mathrm{kDa}$ (pool Il) and $<230 \mathrm{kDa}$ (pool Ill). After being further purified by hydroxyapatite column chromatography and isoelectric focusing. HMW Ig in pool I and LMW Ig in pool Ill were compared with each other by SDS-PAGE under reducing conditions. They were found to be composed of 1 size of heavy chain and 2 sizes of light chain. While HMW Ig in pool I contained $68 \mathrm{kDa} \mathrm{H}$ chains and $22 \mathrm{kDa}$ and $24 \mathrm{kDa}$ L chains, LMW Ig in pool III contained $69 \mathrm{kDa} H$ chains and $22 \mathrm{kDa}$ and $26 \mathrm{kDa}$ L chains. A set of 5 monoclonal antibodies (MAbs) against HMW Igs was prepared. The reactivities of these MAbs with Igs in the 3 pools were determined by enzyme linked immunosorbent assay (ELISA) and dot immunoassay. All 5 MAbs reacted strongly only to the HMW Igs. Results suggest that flounder Igs comprise LMW Igs as well as HMW Igs and the physicochemical and antigenical characteristics of LMW Igs are different from those of HMW Igs.
\end{abstract}

KEY WORDS: Flounder Edwardsiella tarda Immunoglobulin $\cdot$ LMW Ig $\cdot$ HMW Ig

\section{INTRODUCTION}

Immunoglobulin (Ig) synthesized in response to antigenic stimulation is one of the key components of the humoral immune system in vertebrates and has been an object of study for a long time.

In amphibians and higher vertebrates, more than 2 classes of Ig are present and a molecular weight shift from high molecular weight (HMW) to low molecular weight (LMW) Ig commonly occurs during the immune response. In general, 19S pentameric HMW IgM first appears in the early immune response, followed by $7 \mathrm{~S}$ monomeric LMW IgG (Nossal et al. 1964, Rabbitts et al.

- Addressee for correspondence.

E-mail:jwpark@uou.ulsan.ac.kr
1980). Sharks appear to have only 1 class of Ig, i.e. IgM, but a molecular weight shift from $19 \mathrm{~S}$ pentameric to a $7 \mathrm{~S}$ monomeric form of $\operatorname{IgM}$ is thought to occur during the immune response (Marchalonis \& Edelman 1965, Clem \& Small 1967). Recently, some elasmobranchs have been reported to contain a second class of Ig other than IgM (Kobayashi et al. 1984, Kobayashi \& Tomonaga 1988) having more than 2 distinctly different heavy chain isotype genes (Kokubu et al. 1988, Harding \& Amemiya 1990, Harding et al. 1990).

Many teleosts have been reported to possess only 16S tetrameric HMW IgM which has a molecular weight of about $700 \mathrm{kDa}$ (Shelton \& Smith 1970 , Litman 1975, Amemiya \& Litman 1990, Pilstroem \& Petersson 1991), and a molecular weight shift during the immune response has not been reported. However, 
some teleosts possess LMW Igs which are found to be either a monomeric form of HMW Ig or to be a physicochemical form distinct from HMW Ig. For example, goldfish (Uhr et al. 1962, Marchalonis 1971), plaice (Fletcher \& Grant 1969), margate (Clem \& McLean 1975), sheepshead (Lobb \& Clem 1981), and toad fish (Warr 1983) possess LMW IgM, a $7 \mathrm{~S}$ monomeric form of IgM. Other teleosts such as giant grouper (Clem 1971), rainbow trout (Elcombe et al. 1985), channel catfish (Lobb \& Olson 1988), and carp (Rombout et al. 1993) are reported to possess LMW Igs whose $H$ chain is structurally and/or antigenically distinct from that of HMW Ig. However, at present, it is not clear whether or not the LMW Igs of those fishes are a second class of Ig distinct from IgM and are the result of a molecular weight shift during the inumune response.

In this paper, we investigated the humoral immune response in flounder Paralichthys olivaceus to Edwardsiella tarda, a causative agent of edwardsiellosis in fish (Egusa 1976, Nakatsugawa 1983), reported the presence of LMW Ig as well as HMW Ig during an immune response in flounder and concluded that LMW Ig is structurally and antigenically different from HMW Ig.

\section{MATERIALS AND METHODS}

Flounder antisera. Healthy flounders Paralichthys olivaceus weighing about $110 \mathrm{~g}$ were maintained in filtered seawater at 20 to $23^{\circ} \mathrm{C}$. Five fish were intraperitoneally injected once with formalin-killed Edwardsiella tarda prepared from a strain (FSW-910410) isolated from a flounder in Korea (Bang et al. 1992). The bacterin dose contained about $4 \times 10^{9}$ bacterial cells per fish. These fish were bled periodically from the caudal artery; the serum was collected after centrifugation and stored at $-20^{\circ} \mathrm{C}$.

Agglutination test. Antiserum or purified antibody solutions were 2-fold serially diluted with phosphatebuffered saline (PBS) and mixed with an equal volume of formalin-killed bacterial cells (approximately $2.0 \times$ $10^{8}$ cells $\mathrm{ml}^{-1}$ ) in a round bottom multiwell plate (Green Cross, Korea) and incubated for $2 \mathrm{~h}$ at room temperature. The end point of titrations were indicated by macroscopic settling patterns of the bacterial cells

Column chromatography. The proteins in $3 \mathrm{ml}$ of sera were precipitated with sodium sulfate $(18 \% \mathrm{w} / \mathrm{v})$ at room temperature and collected by centrifugation at $3000 \times g$ for $30 \mathrm{~min}$ at $25^{\circ} \mathrm{C}$. The precipitates were dialyzed using PBS (0.14 M NaCl, $2.7 \mathrm{mM} \mathrm{KCl}, 1.5 \mathrm{mM}$ $\mathrm{KH}_{2} \mathrm{PO}_{4}, 8.1 \mathrm{mM} \mathrm{Na}_{2} \mathrm{HPO}_{4}, \mathrm{pH} .4$ ) at $4^{\circ} \mathrm{C}$. Sephacryl $\mathrm{S}-300$ (Sigma, USA) gel in a $1.5 \times 120 \mathrm{~cm}$ column was equilibrated with PBS, and flounder serum proteins were eluted with the same buffer at a flow rate of $20 \mathrm{ml}$ $h^{-1}$. The samples were collected at a volume of $1.0 \mathrm{ml}$ per tube and analyzed for protein by measuring optical density at $280 \mathrm{~nm}\left(\mathrm{OD}_{280}\right)$ and Ig quantity using the agglutination test and ELISA. In order to estimate the approximate molecular weights of the proteins fractionated on gel-filtration, standard size marker proteins such as blue dextran $(2000 \mathrm{kDa})$, thyroglobulin (669 kDa) and catalase (232 kDa) (Pharmacia, Sweden) were eluted under the same conditions as described above. The fractions with agglutination titers were pooled and dialyzed using $0.01 \mathrm{M} \mathrm{K}_{2} \mathrm{HPO}_{4}(\mathrm{pH} 8.0)$ and injected into a hydroxyapatite column $(1.0 \times 25 \mathrm{~cm})$ equilibrated with $0.01 \mathrm{M} \mathrm{K}_{2} \mathrm{HPO}_{4}(\mathrm{pH} 8.0$ ). Elution was carried out using a linear gradient from 0.01 to $0.5 \mathrm{M}$ $\mathrm{K}_{2} \mathrm{HPO}_{4}$ at a flow rate of $15 \mathrm{ml} \mathrm{h}^{-1} ; 1.5 \mathrm{ml}$ fractions were collected and analyzed for protein $\left(\mathrm{OD}_{280}\right)$ and agglutination titer.

Isoelectric focusing. Flounder Igs were further purified by isoelectric focusing. The Igs were separated in $\mathrm{pH} 3.5$ to 10 isoelectric focusing gel and purified by electroelution with a gel eluter (Hoeffer, USA).

Monoclonal antibodies (MAbs). MAbs against HMW Igs were prepared by a modification of the methods described by Lane (1985). Briefly, balb/c mice were immunized intraperitoneally 4 times with purified HMW Igs mixed with Freund's adjuvant (Sigma) and received an additional intravenous injection 3 to 4 d before fusion. Spleen cells from immunized mice were fused with SP-2/0 myeloma cells in 50\% polyethylene glycol 1500 (Sigma). The cells were resuspended in RPMI-1640 medium containing hypoxanthine, aminopterin, thymidine and $10 \%$ fetal bovine serum (Gibco BRL, USA) and plated in 96-well culture plates. Hybridoma supernatants were screened using ELISA. Selected hybridomas were cloned a minimum of 2 times by limiting dilution on macrophage feeder cells and then expanded in a culture flask for in vitro production of monoclonal antibodies.

MAb class was determined by using a mouse monoclonal sub-isotyping kit (GibcoBRL, USA).

Enzyme-linked immunosorbent assay (ELISA). The reactivities of MAbs with flounder Igs were assayed by an ELISA. Microtiter plates (Nunc, Denmark) were coated with $2 \mu \mathrm{g}$ protein $\mathrm{ml}^{-1}$ of flounder Igs in coating buffer (0.5 M carbonate-bicarbonate, $\mathrm{pH} 9.6$ ) at $4^{\circ} \mathrm{C}$ for $16 \mathrm{~h}$. The plates were blocked with $1 \%$ bovine serum albumin (BSA) in PBS for $1 \mathrm{~h}$ at room temperature. After washing, MAbs diluted $1 / 50$ in PBS containing $0.05 \%$ Tween 20 were added, incubated for $2 \mathrm{~h}$ and washed 3 times with PBS-Tween 20 $(0.05 \%)$. Alkaline phosphatase-conjugated goat antimouse IgG (Sigma) was added and was detected by the addition of alkaline phosphatase substrate, $p$-nitrophenyl phosphate $\left(1 \mathrm{mg} \mathrm{ml} \mathrm{m}^{-1}\right.$ in $0.1 \mathrm{M} \mathrm{NaHCO}_{3}$ and $1.0 \mathrm{mM} \mathrm{MgCl}$, pH 9.8). The absorbance was read at $405 \mathrm{~nm}$. 
For the quantification of anti-Edwardsiella tarda Igs in flounder sera, microplates were coated with $2 \mathrm{mg}$ proteins $\mathrm{ml}^{-1}$ of E. tarda cells lysate. Then 2 -fold serially diluted flounder sera was added to microtiter plates and was reacted successively with rabbit antiflounder Igs and goat anti-rabbit IgG conjugated with alkaline phosphatase. The bound alkaline phosphatase was detected by the addition of $p$-nitrophenyl phosphate.

Electrophoresis. SDS-PAGE was performed by the method of Laemmli (1970). Serum proteins were electrophoresed using the discontinuous buffer system in $5 \%$ polyacrylamide gel under non-reducing conditions and $10 \%$ polyacrylamide gel under reducing conditions. The gels were stained with $0.1 \%$ Coomassie Brilliant Blue, destained and then dried. The molecular weights of the polypeptides were calculated from their electrophoretic mobilities relative to standard proteins (Bio-Red, USA) run in parallel. Bovine IgG and IgM (Sigma) were used as reference standards.

Western blots and dot immunoassay. Electrophoretically separated polypeptides were transferred to nitrocellulose (NC) paper at $40 \mathrm{~mA}$ for $16 \mathrm{~h}$ using a transfer buffer of $25 \mathrm{mM}$ Tris, $192 \mathrm{mM}$ glycine, $20 \%$ methanol, pH 8.3. The NC paper was blocked with $1 \%$ BSA in PBS. After incubation of mouse MAbs for $2 \mathrm{~h}$, bound antibodies were detected with alkaline phosphatase-conjugated goat anti-mouse IgG antibodies followed by the addition of BCIP/NBT phosphatase substrate, consisting of 5-bromo-4-chloro-3-indolyl phosphate sodium salt $\left(0.15 \mathrm{mg} \mathrm{ml}^{1}\right)$ and $p$-nitro blue

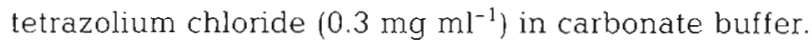

For the dot immunoassay, $1 \mu \mathrm{g}$ protein of flounder Ig was dotted to NC paper. After the dots had been allowed to dry, the NC paper was blocked and incubated with MAb and alkaline phosphatase-conjugated goat anti-mouse IgG as described above.

\section{RESULTS}

\section{Immune response}

The humoral immune response of flounder immunized once with formalin-killed Edwardsiella tarda was examined by testing the anti-E. tarda agglutination titers in the sera collected from 5 fish once a week (Fig. 1). The agglutination titer was detected in the sera collected 1 wk post-immunization and increased continuously reaching maximum levels by Week 5 . The agglutination titers remained at maximum levels until Week 7 after immunization, at which time they started to decrease gradually for the remainder of the experiment. However, the anti-E. tarda agglutination titer remained relatively high after $16 \mathrm{wk}$ had passed

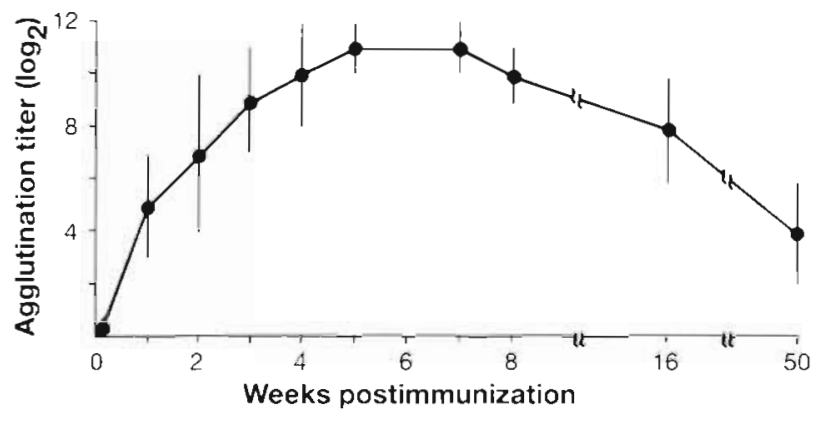

Fig. 1 Anti-Edwardsiella tarda agglutination titers of sera taken from flounder immunized once with formalin-killed E. tarda cells. Each data point represents the mean $\pm \mathrm{SE}$ agglutination titer from 5 fish

and did not return to background levels until 1 yr after the start of the experiment.

\section{Elution profile of gel filtration}

Flounder sera were fractionated by using gel filtration in order to ascertain whether various sizes of Igs, from HMW Ig to LMW Ig, appeared during the immune response.

Flounder sera from 5 fish were collected and pooled at $1,2,4,5$ and 16 wk post-immunization, and $3 \mathrm{ml}$ of each sera pool was passed over a Sephacryl S-300 column. The elution profile and the agglutination titers are shown in Fig. 2. All the sera collected at different periods post-immunization were separated into 4 peaks. Based on the elution of the molecular weight standards, the 4 peaks were ascribed molecular weight ranges (Fig, 2A). The first peak contained molecular weights greater than $700 \mathrm{kDa}$, the second ranged from 230 to $700 \mathrm{kDa}$, and the third and the fourth peaks were less than $230 \mathrm{kDa}$.

The distributions of the anti-Edwardsiella tarda Igs were not constant among the antisera collected at different periods. In antiserum collected at $1 \mathrm{wk}$ postimmunization, E. tarda agglutinating activities were detected only in the first peak (Fig. 2A). This seemed to be HMW Ig with a molecular weight of more than $700 \mathrm{kDa}$. But with time, even though most of the flounder E. tarda agglutinating activity involved HMW Ig, LMW Ig with E. tarda agglutinating activity could be detected, and by 4 to 5 wk post-immunization the agglutination activity was distributed among the first, second and even the third peak (Fig. 2B, C \& D). However, in the serum collected at $16 \mathrm{wk}$, the agglutination activity was again only detectable in the first peak (Fig. 2E).

Using agglutination assay, LMW Igs were not detected during the early (1 wk post-immunization) and the late (16 wk post-immunization) immune response. 


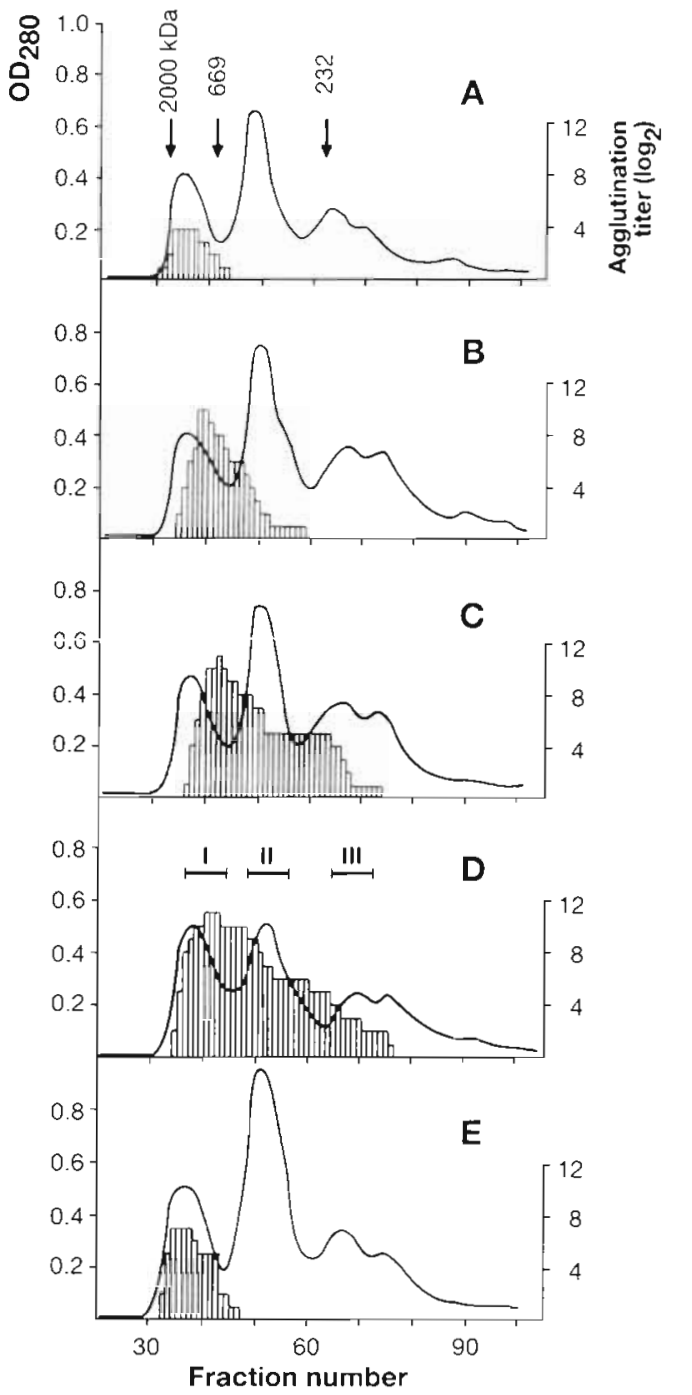

However, it was probable that LMW Igs might be produced during the entire response but that agglutination assay was not sensitive enough to detect the low concentration of LMW Igs during the early and the late immune response. A more sensitive assay, ELISA, was employed to detect any LMW Igs present at a low concentration during the early and the late immune response. Using ELISA, LMW Ig with Edwardsiella tarda binding activities in the second and the third peaks as well as HMW Ig in the first peak were detected in the sera collected during the early and the late immune response (Fig. $2 F \& G$ ). This result supports the idea that LMW Ig and HMW Ig are present during the entire immune response.

\section{SDS-PAGE of flounder Igs}

The eluted fractions of flounder serum at 5 wk showing agglutination activity were combined into 3 pools

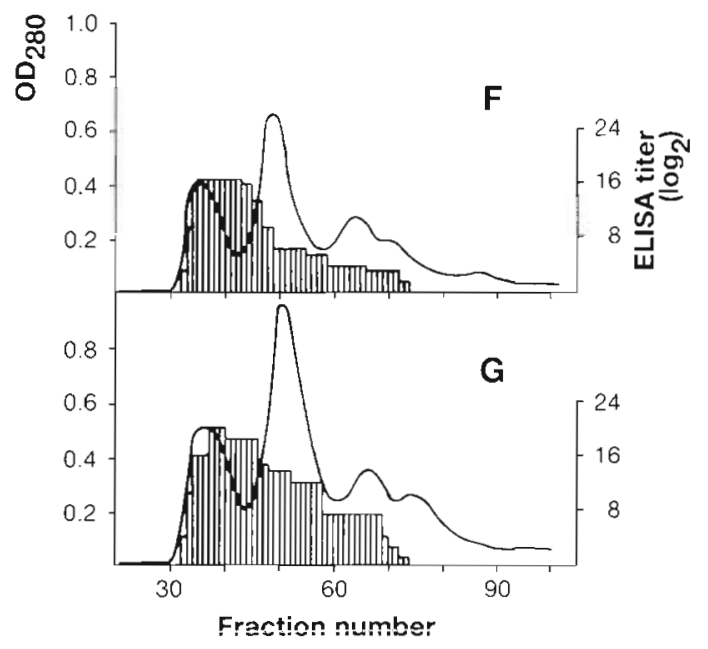

Fig. 2. Elution profile of flounder anti-Edwardsiella tarda serum from a Sephacryl S-300 column. Flounder sera were collected from the tail vein of flounders at (A) $1 \mathrm{wk}$, (B) $2 \mathrm{wk}$, (C) $4 \mathrm{wk}$, (D) $5 \mathrm{wk}$, and (E) $16 \mathrm{wk}$ post-immunization with formalin-killed E. tarda cells. Each fraction was analyzed for proteins and Ig quantity using the agglutination test $(A, B, C$, $D$, and $E$ ) or ELISA ( $F$ and $G$ ). Lines indicate absorbance at $280 \mathrm{~nm}$ and bars indicate the antibody titer. To determine the approximate molecular weight of the eluted proteins, 3 standard size marker proteins (blue dextran, $2000 \mathrm{kDa}$; thyroglobulin, $669 \mathrm{kDa}$; catalase, $232 \mathrm{kDa}$ ) were used and their positions indicated with arrows in (A). In D, I, II, III indicate pools I, II and III (see 'SDS-PAGE of flounder Igs)

according to their molecular weight: pool I contained the first peak; pool II, the second peak $k_{i}$ pool III, the first portion of the third peak (Fig, 2D). Then, each pooled fraction was further purified by hydroxyapatite gel column chromatography and elution from the gel by isoelectric focusing.

In order to elucidate the purity and to compare the relative size of Igs in each pool, these pools were analyzed by SDS-PAGE under non-reducing conditions. As shown in Fig. $3 \mathrm{~A}$, only 1 band was observed from each pool and the sizes were different from each other, pool I > pool II > pool III. Then, the polypeptides of the HMW Igs in pool I and the LMW Ig, in pool III were analyzed by SDS-PAGE under reducing conditions. As shown in Fig. 3B, Igs in each pool were composed of $1 \mathrm{H}$ chain and $2 \mathrm{~L}$ chains and the sizes of these chains of LMW Ig were different from those of HMW Ig. While the HMW Ig in pool I contained a $68 \mathrm{kDa} \mathrm{H}$ chain and $22 \mathrm{kDa}$ and $24 \mathrm{kDa}$ $\mathrm{L}$ chains, the LMW Igs in pool III contained a $69 \mathrm{kDa}$ 
Fig. 3. Electrophoretical analysis of flounder immunoglobulins. Flounder immunoglobulins were purified by hydroxyapatite column chromatography and isoelectric focusing. Purified immunoglobulins, HMW Igs (pool I) and LMW Igs (pools II and III), were analyzed by (A) $5 \%$ SDS-PAGE under non-reducing conditions and (B) $10 \%$ SDS-PAGE under reducing conditions, and visualized by Coomassie staining. Values on $y$-axis are $\mathrm{kDa}$. Lanes 1 and 2 of $(\mathrm{B})$ are bovine $\lg G$ and $\operatorname{Ig} M$ respectively. $\mathrm{H}$ : $\mathrm{H}$ chain; L: L chain

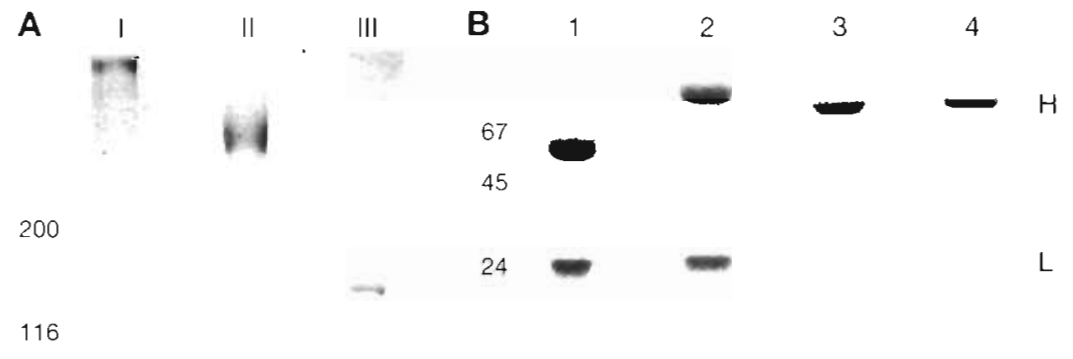

$\mathrm{H}$ chain and $22 \mathrm{kDa}$ and $26 \mathrm{kDa} \mathrm{L}$ chains. This result implies that HMW Ig and LMW Ig are composed of different sizes of $\mathrm{H}$ and $\mathrm{L}$ chains.

\section{Reactivities of different-sized Igs with MAbs}

In order to compare the antigenicity of Igs in the 3 pools, a panel of 5 MAbs was prepared from a balb/c mouse immunized with HMW Igs in pool I. These MAbs were named AE10, AF7, AG9, BH8, and BH11 Among these 5 MAbs, 1 MAb, BH11, reacted with both $\mathrm{H}$ and $\mathrm{L}$ chains of HMW Ig but the other 4 reacted only with the H chain of HMW Ig (Fig. 4). The reactivities of these MAbs with different-sized Igs in the 3 pools were determined by ELISA and dot blot immunoassays. In ELISA, even though 1 MAb, BH11, showed equal reactivity with both HMW Ig in pool I and LMW Ig in pool II, the other 4 MAbs showed strong reactivities only with HMW Ig (Fig. 5A). In dot immunoassay, all the 5 MAbs reacted strongly only with the HMW Ig in pool I (Fig. 5B). The results revealed that the epitopes recognized by these MAbs were specific to the HMW Ig.

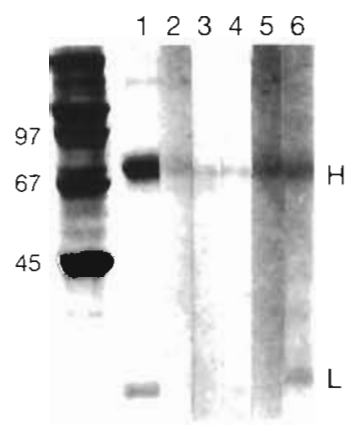

Fig. 4. Immunoglobulin polypeptides recognized by monoclonal antibodies (MAbs). Five MAbs against HMW Ig (pool I) were prepared and the reactivities of these MAbs with the HMW Ig were analyzed by Western blots. Lane 1: polypeptides of $\mathrm{HMW}$ Ig stained with Coomassie Blue; lane 2: MAb AF7; lane 3: MAb AE10; lane 4: MAb AG9; lane 5: MAb BH8; lane 6: MAb BH11. The first lane is the standard. Values on $y$-axis are $\mathrm{kDa}$. H: H chain; L: L chain

\section{DISCUSSION}

The present study was conducted to determine whether or not various sizes of Igs were present in flounder during an immune response and, if so true, whether or not these different-sized Igs were the same class with different molecular weights.

In order to answer the first question, sera collected at various times post-immunization with Edwardsiella tarda were fractionated by gel filtration and each of the fractions was analyzed for the presence of Igs using an agglutination test. The fractions with agglutination activities were assigned to 3 pools based on size: pool I $>700 \mathrm{kDa}, 230 \mathrm{kDa}<$ pool II $<700 \mathrm{kDa}$ and pool III < $230 \mathrm{kDa}$. Early and late sera, collected at 1 and $16 \mathrm{wk}$, contained HMW Igs only in pool I. However, by 4 and 5 wk post-immunization, LMW Igs in pools II and III were detected even though the HMW Igs were at a consistently higher concentration than the LMW Igs. When these HMW and LMW Igs were analyzed by SDS-PAGE under non-reducing conditions, they were detected as distinct bands of different sizes with pool I $>$ pool II > pool III, as could be predicted from the results of gel filtration. This indicated the presence of various sizes of Igs in flounder during the immune response.

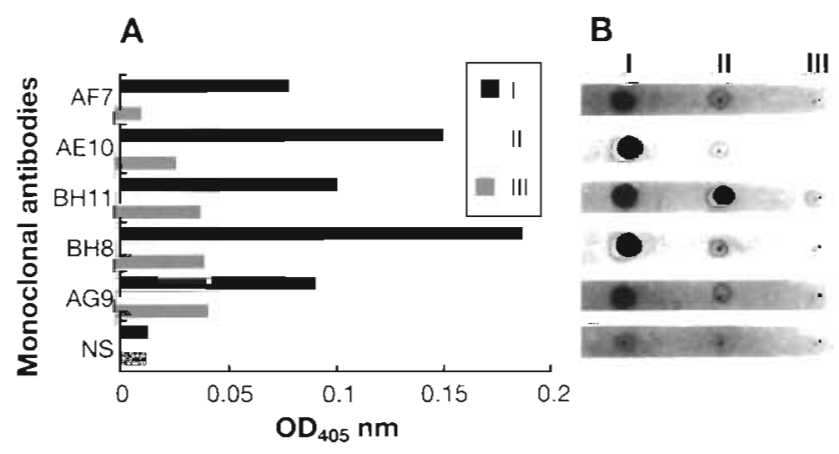

Fig. 5. Reactivity of 5 MAbs with flounder immunoglobulins. Flounder immunoglobulins, HMW Ig (I) and LMW Ig (II and III), captured on the microtiter plates were reacted with 5 MAbs and the amount of protein-bound MAbs were determined by (A) ELISA and (B) dot immunoassay. I, II, III (B) indicate pools I, II and III. Normal mouse serum (NS) was used as a control 
In flounder, the LMW Igs with agglutination activity appeared approximately 4 wk post-immunization. These results suggested that LMW Ig could be produced only during active immune response. However, it is more probable that both HMW and LMW Igs coexist during the entire response but that the concentration of the LMW Igs during the early and late immune response would be too low to be detected by agglutination assay. To clarify this, a more sensitive assay, ELISA, was employed and, as a result, the LMW Igs in pool II and III as well as HMW Ig in pool I were detected in the sera collected during the early and the late immune response. This result supports the coexistence of HMW and LMW Igs during the entire immune response. However, even though most of the antibody activity throughout the immune iesponise irvolved HMW Ig, the concentration of LMW Ig seemed to increase more rapidly than HMW Ig during the immune response. This suggests the possible presence of a molecular weight shift.

The possibility that the LMW Igs may be the products of in vitro degradation of HMW Igs could be ruled out due to the fact that the $\mathrm{H}$ and L chains of LMW Igs were larger than those of HMW Igs and the antigenic determinants of HMW Igs were distinct from those of LMW Igs. This is discussed below.

Many fishes are known to possess LMW Igs. Some LMW Ig is found to be a monomeric form of HMW IgM. However, some fishes possess LMW Igs structurally and antigenically distinct from HMW IgM. For example, skate, a cartilaginous fish, possesses LMW Igs whose $\mathrm{H}$ chains are structurally and antigenically distinct from a $\mu$ chain (Kobayashi et al. 1984, Kobayashi \& Tomonaga 1988) and have more than 2 distinctly different $\mathrm{H}$ chain isotype genes (Harding \& Amemiya 1990, Harding et al. 1990). Among teleosts, giant grouper (Clem 1971), rainbow trout (Elcombe et al. 1985), channel catfish (Lobb \& Olson 1988), and carp (Rombout et al. 1993) possess LMW Ig whose $\mathrm{H}$ chain is structurally and/or antigenically distinct from that of HMW Ig

Our next question is whether or not LMW Igs in flounder are the cleavage products of HMW Igs or are physicochemically distinct from HMW Ig. The evidence presented here demonstrates that, in flounder, the LMW Igs are structurally and antigenically distinct from HMW Ig on the basis of 2 criteria. Firstly, LMW Igs possess $\mathrm{H}$ and $\mathrm{L}$ chains whose sizes are different from those of HMW Ig. While the HMW Ig in pool I contained a $68 \mathrm{kDa} \mathrm{H}$ chain and $22 \mathrm{kDa}$ and $24 \mathrm{kDa}$ L chains, the LMW Ig in pool III contained a $69 \mathrm{kDa}$ $\mathrm{H}$ chain and $22 \mathrm{kDa}$ and $26 \mathrm{kDa} \mathrm{L}$ chains. The presence of multiple L chains in flounder Igs is not unique, but several fishes have previously been reported to possess multiple L chains with a molecular weight of 22 to
26 kDa (Lobb \& Clem 1983, Warr 1983, Lobb et al. 1984, Rast et al. 1994). In channel catfish, 3 molecular weight $L$ chain variants with molecular weights of 22 , 24 and $26 \mathrm{kDa}$ were observed and grouped into 2 classes based on their reactivities with MAbs (Lobb et al. 1984), and several $C$ region gene segments of the L chain were found (Ghaffari \& Lobb 1993). At present, there is no data comparing the similarities between the $L$ chains of flounder and those of other fishes. Secondly, the $\mathrm{H}$ chains were antigenically different. A set of 5 MAbs was prepared from a balb/c mouse immunized with HMW Ig in pool $\mathrm{I}$. They were found to recognize the $H$ chains of the HMW Igs. When the reactivities of these MAbs with different-sized Igs in the 3 pools were determined by ELISA and dot imInunuassay, they were immunoreactive with HMW Ig but were not or hardly immunoreactive with other LMW Igs in pool II and pool III. Even though it is not now certain whether the MAbs recognize the determinants in the constant region or variable region of $\mathrm{H}$ chain, this clearly shows that LMW Igs are somehow antigenically different from HMW Ig.

A]though the physicochemical studies reported here on flounder Igs are somewhat limited, it seems reasonable to suggest the gross architecture of flounder Igs. During an active immune response, flounder possess various sizes of Igs which are detected as bands on polyacrylamide gel under non-reducing conditions. The Igs in pool III are considered to be a bivalent monomeric type of Ig composed of $2 \mathrm{H}-2 \mathrm{~L}$ chains with an approximate molecular weight of $182 \mathrm{kDa}$ and/or $190 \mathrm{kDa}$, since this type of $\mathrm{Ig}$ is able to agglutinate bacterial cells (monovalent Ig is unable to agglutinate cells), had $\mathrm{H}$ chains of $69 \mathrm{kDa}$ and $\mathrm{L}$ chains of 22 and $26 \mathrm{kDa}$ as determined by SDS-PAGE, and was smaller than $230 \mathrm{kDa}$ as determined by gel filtration. Similar reasoning suggests that the Igs in pool II are dimer ( $4 \mathrm{H}-4 \mathrm{~L}$ ) and/or trimer ( $6 \mathrm{H}-6 \mathrm{~L}$ ) with a molecular weight of about $360 \mathrm{kDa}$ and/or $540 \mathrm{kDa}$ respectively and that the largest Igs in pool I are tetramer $(8 \mathrm{H}-8 \mathrm{~L})$ with a molecular weight of $720 \mathrm{kDa}$. Although there is no data which allow direct comparisons, the tetrameric HMW Ig of flounder seems to belong to the same class as that seen in other teleosts, IgM.

In conclusion, even though the tetrameric form of IgM made up most of the Igs throughout the immune response of flounder against Edwardsiella tarda, LMW Igs with monomeric, dimeric and trimeric forms consistently coexisted during the immune response. HMW Ig and LMW Ig were composed of different sizes of $\mathrm{H}$ and $L$ chains and were antigenically distinct from each other, which suggests the possible presence of a different class or subclass of Igs. To further examine this possibility, peptide mapping and amino acids sequencing studies are presently being conducted. 
Acknowledgements. We thank Dr J. L. Fryer and Dr S. Kaattari for discussions and J. W. Do and I. S. Choi for technical assistance. This work was supported in part by grants from the Genetic Engineering Research Program and from the Ministry of Agriculture, Forestry and Fisheries.

\section{LITERATURE CITED}

Amemiya CT, Litman GW (1990) Complete nucleotide sequence of an immunoglobulin heavy-chain gene and analysis of immunoglobulin gene organization in a primative teleost species. Proc Natl Acad Sci USA 87:811-815

Bang JD, Chun SG, Park SI, Choi YJ (1992) Studies on the biochemical and serological characteristics of Edwardsiella tarda isolated from cultured flounder (Paralichthys olivaceus). J Fish Pathol 5:29-35

Clem LW (1971) Phylogeny of immunoglobulin structure and function. IV. Immunoglobulins of the giant grouper. J Biol Chem 246:9-15

Clem LW, McLean WE (1975) Phylogeny of immunoglobulin structure and function. VII. Monomeric and tetrameric immunoglobulins of the margate, a marine teleost fish. Immunology 29:791-799

Clem LW, Small PA (1967) Phylogeny of immunoglobulin structure and function. I. Immunoglobulin of the lemon shark. J Exp Med 125:893-920

Egusa S (1976) Some bacterial diseases of freshwater fishes in Japan. Fish Pathol 10:103-114

Elcombe BM, Chang RJ, Taves CJ, Winkelhake JL (1985) Evolution of antibody structure and effector functions: comparative hemolytic activities of monomeric and tetrameric lgM from rainbow trout, Salmo gairdneri. Comp Biochem Physiol 80B:697-706

Fletcher TC, Grant PT (1969) Immunoglobulins in the serum and mucous of the plaice (Pleuronectes platessa). Biochem J 115

Ghaffari SH, Lobb CJ (1993) Structure and genomic organization of immunoglobulin light chain in the channel catfish: an unusual genomic organizational pattern of segmental genes. J Immunol 151:6900-6912

Harding FA, Amemiya CT (1990) Two distinct immunoglobulin heavy chain isotypes in a primative, cartilaginous fish, Raja erinacea. Nucleic Acids Res 18(21):6369-6376

Harding FA, Cohen N, Litman GW (1990) Immunoglobulin heavy chain gene organization and complexity in the skate, Raja erinacea. Nucleic Acids Res 18(4):1015-1020

Kobayashi $K$. Tomonaga $S$ (1988) The second immunoglobulin class is commonly present in cartilaginous fish belonging to the order Rajiformes. Mol Immunol 25: $115-120$

Kobayashi K, Tomonaga S, Kajii T (1984) A second class of immunoglobulin other than IgM present in the serum of a cartilaginous fish, the skate, Raja kenojei: isolation and characterization. Mol Immunol 21:397-404

Kokubu $F$, Hinds $K$, Litman $R$, Shamblott MJ, Litman GW (1988) Complete structure and organization of immuno-

Responsible Subject Editor: D. W. Bruno, Aberdeen, Scotland, UK globulin heavy chain constant region genes in a phylogenetically primative vertebrate. EMBO J 7:1979-1988

Laemmli UK (1970) Cleavage of structural proteins during the assembly of the head of bacteriophage T4. Nature 227 $680-685$

Lane RD (1985) A short-duration polyethylene glycol fusion technique for increasing production of monoclonal antibody-secreting hybridomas. J Immunol Methods 81: 223-228

Litman GW (1975) Physical properties of immunoglobulins of lower species: a comparison with immunoglobulins of mammals. In: Marchalonis JJ (ed) Comparative immunology Blackwell Scientific Publications, Oxford, p 239-275

Lobb CJ, Clem LW (1981) Phylogeny of immunoglobulin structure and function. $X$. Humoral immunoglobulins of the sheepshead, Archosargus probatocephalus. Dev Comp Immunol 5:271-282

Lobb CJ, Clem LW (1983) Distinctive subpopulations of catfish serum antibody and immunoglobulin. Mol Immunol 20:811-818

Lobb CJ, Olson MOJ (1988) Immunoglobulin heavy chain isotypes in a teleost fish. J Immunol 141:1236-1245

Lobb CJ, Olson MOJ, Clem LW (1984) Immunoglobulin light chain classes in a teleost fish. J Immunol 132:1917-1923

Marchalonis J (1971) Isolation and partial characterization of immunoglobulins of goldfish and carp. lmmunology 20: 161-173

Marchalonis J, Edelman GM (1965) Phylogenetic origins of antibody structure. 1. Multichain structure of immunoglobulins of the smooth dogfish. J Exp Med 122:610-618

Nakatsugawa T (1983) Edwardsiella tarda isolated from cultured young flounder. Fish Pathol 18:99-101

Nossal GJV, Szenberg A, Ada GL, Austin CM (1964) Single cell studies on $19 \mathrm{~S}$ antibody production. J Exp Med 119: $485-502$

Pilstrom L, Petersson A (1991) Isolation and partial characterization of immunoglobulin from cod (Gadus morhua L.). Dev Comp Immunol 15:143-152

Rabbitts TH, Forster A, Dunnick W, Bentley DL (1980) The role of gene deletion in the immunoglobulin heavy chain switch. Nature 283:351-356

Rast JP, Anderson MK, Ota T, Litman RT, Margittai M, Shamblott MJ, Litman GW (1994) Immunoglobulin light-chain class multiplicity and alternative organizational forms in early vertebrate phylogeny. Immunogenetics 40:83-99

Rombout JHWM, Taverne N, Vandekamp M, Tavernethiele AJ (1993) Differences in mucus and serum immunoglobulin of carp (Cyprinus carpio L). Dev Comp Immunol 17 : $309-317$

Shelton E, Smith M (1970) The ultrastructure of carp (Cyprinus carpio) immunoglobulin: a tetrameric macroglobulin. J Mol Biol 54:615-617

Uhr JW, Finkelstein MS, Franklin EC (1962) Antibody response to bacteriophage $X 174$ in non-mammalian vertebrates. Proc Soc Exp Biol Med 111:13-15

Warr GW (1983) Immunoglobulin of the toadfish Spheroides glaber. Comp Biochem Physiol 76:507-514

Manuscript first received: December 11, 1995

Revised version accepted: March 12, 1996 